\title{
Correspondence
}

\section{England expects: more than we can provide}

\section{DeAR SiRS}

The past 12 months have seen a continuation of the difficulties we have encountered throughout the 1980 s in finding sufficient numbers of appropriately trained and motivated candidates to take on consultant posts responsible for developing and running services for the elderly mentally ill. In a way, matters have seemed more unsettling when Health Authorities, desperate to appoint someone, have insisted on holding appointment committees when none of the candidates were judged by the College representative to be worthy of shortlisting. In at least one case an appointment has been recommended by an appointment committee and confirmed by a Regional Health Authority despite the College's advice that the candidate was not yet sufficiently trained to take up the appointment.

In addition a new dimension to the manpower problem has appeared, for colleagues on general psychiatry committees have begun to bewail the dearth of suitably qualified applicants for consultant posts throughout the country. If general psychiatry is falling upon hard times it seems likely that 'old age psychiatry' will suffer further by the competition for scarce talent. There is a very real concern that consultants are being appointed to posts in both old age and general psychiatry without having completed as much training in their chosen speciality as would be advisable with a career of 30 years or more ahead of them. Review of consultant appointments advertised in the British Medical Journal has its limitations, but gives a crude estimate of the demand for specialists (Jolley, 1988). Comparing the demand during the 12 calendar months of 1988 with findings from a 12-month period 1986-87 is revealing (Table I).

Posts advertised in psychotherapy, forensic psychiatry, childhood and adolescence, mental handicap and psychogeriatrics have remained at a similar level.

Within the psychogeriatric field more posts appear to be asking for true specialists rather than 'with an interest'.

The most notable change is a $30 \%$ increase in the number of general psychiatry posts compared with the previous 12 months. Some of these posts specify a requirement for 'interest' in rehabilitation, drugs and alcohol, etc. but rather less than in the previous year.
TABLE I

Consultant vacancies psychiatry: British Medical Journal 12 month periods 1986-87, 1988

\begin{tabular}{lcc}
\hline England and Wales & $1986-87$ & 1988 \\
\hline General psychiatry & 56 & 84 \\
General psychiatry +interest & & \\
$\quad$ (not OA) & 38 & 43 \\
Psychogeriatrics & 43 & 55 \\
General psychiatry and old age & 16 & 7 \\
Psychotherapy & 10 & 8 \\
Forensic & 10 & 14 \\
Child and adolescent & 43 & 39 \\
Handicap & 25 & 21 \\
Private & 4 & 1 \\
\end{tabular}

Posts advertised may be newly created or arise because a previous holder has retired, died or moved on to another post. The overall expansion in consultant posts in psychiatry is less than $4 \%$ and cannot explain the increase in the number of advertisements. Anecdote suggests that most of the extra demand is being created by consultants retiring in their fifties or early sixties, taking advantage of their Mental Health Officer status. This is taken by many to reflect widespread unhappiness among established consultants with the working conditions that they now find themselves in with the destruction of useful and usable services and their replacement by shabby, ill conceived and underfunded 'community alternatives'. It would be useful to confirm that this is the case - for it provides strong suggestive evidence that some rethinking might be appropriate.

Fifteen general psychiatry posts and eight old age posts were readvertised at least once within 1988. The continuing demand for old age psychiatrists is confirmed when its 62 posts are compared with those advertised in general medicine ( 59 posts) and geriatric medicine ( 43 posts) in England and Wales in the same period.

From the point of view of manpower planning, the present figures suggest that the JPAC quota of senior registrars for general psychiatry and old age psychiatry combined is insufficient to fulfil the need for trained specialists.

It will probably be helpful to 'budget' separately for general psychiatry and old age psychiatry with 
identified general and old age JPAC quotas. It is necessary to monitor posts that come 'on the market' and the departures that release them on an annual basis - so that training opportunities can be modified in response to actual as opposed to planned need.

\section{Withington Hospital \\ West Didsbury \\ Manchester}

\section{Reference}

JOLLEY, D. (1988) England expects: are we prepared? Bulletin of The Royal College of Psychiatrists, 12 , 102-103.

\section{Psychiatry and the private sector}

\section{DeAr Sirs}

As a consultant psychiatrist, working in one of the more notoriously deprived inner London boroughs, I was saddened at Dr Birley's response to the open letter objecting to a session on Private Psychiatry at the Autumn Quarterly Meeting (Psychiatric Bulletin, December 1988, 12, 554). The key points made by the letter's signatories were the non-academic aspects of the topic, the promotional interests of some of the speakers, and the NHS as "the only option for the vast majority of our patients". To reply with unnecessary defensiveness, that "private care is a legitimate business" - whoever said it was not? - and that it "makes a contribution to the care of our citizens" is banal and beside the point.

The key question is whether private practice, per $s e$, has any particular academic contribution to make to psychiatry that cannot be, or is not being, made in the NHS. The subsidiary, but equally vital, point is the economic status of those suffering from significant mental illness which by definition largely puts them out of reach of private care. This is not a "matter of debate" but an established aspect of social psychiatric research.

What I find so annoying about modern private psychiatry is the false hope and guilt engendered in patients and relatives, who fear that if they just paid enough money a chronic schizophrenic illness would somehow be resolved. Those unable to think clearly or judge appropriately, because of illness, are especially vulnerable to such notions. Yet never once has a private practitioner contacted me or my colleagues for a detailed background history of patients well-known to us, yet referred by, for example, an inexperienced GP or GP locum.

In my experience the main contribution of those working in the private sector has been despair, not care. The contrast between the crumbling Victorian infirmary in which I write and the glossy brochures of new private hospitals is especially discomforting. Were they to consider researching such aspects of the outcome of private referral, I might be prepared to listen to their presentations.

\section{Hackney Hospital}

London E9

T. H. TURNER

\section{DeAR SirS}

As one who has for many years worked solely as a private practitioner in psychiatry, I can still have some sympathy with and understanding of the concern expressed by Appleby et al (Psychiatric Bulletin, December 1988), although I feel that their expression of it does not really reflect the basis for their distaste and is a little inappropriate.

It must surely be agreed that the prime objective of psychiatry (as indeed of all other branches of medicare) is to provide the best possible service to the patient. The method of remuneration should be immaterial. Thus psychiatry in private practice is in general not characterised by problems that do not arise in any other community-based service and as such is not a separate academic discipline. However, the same is true of practice in a Government service.

The consideration of the nature and funding of services and their impact on treatment is a legitimate object of scientific study and in psychiatry dates from the time of Freud.

Any sessions that meet this criterion will not affect either our academic reputation or our ethical one.

Suite 1

GORDON R. W. DAvies

1 Darling Street

Wollongong, Australia

\section{A medical member's analysis of 50 patients at the Mental Health Review Tribunal}

\section{DeAr Sirs}

As a medical member of the Mental Health Review Tribunal (MHRT) for Yorkshire, I have analysed a series of 50 consecutive cases that I have examined in the four-year period 1985 to 1988.

\section{Findings}

Sex: There were 26 men and 24 women, total 50.

Age ranges: Twenty-two (15 men, seven women) were in the 20 to 35 age range, including 14 (nine men, five women) aged 26 to 30 . Seven (four men, three women) were in the 36 to 40 age group. Twenty-one (seven men, 14 women) were aged from 41 to 85 , including one woman in the 66 to 70 age group, one woman 71 to 75 and one woman 81 to 85 . 